\title{
MARKERS OF EMPHYSEMA ARE ASSOCIATED WITH MORE SEVERE CHRONIC OBSTRUCTIVE PULMONARY DISEASE
}

Piera Boschetto $\mathrm{MD}^{1}$, Sonia Quintavalle $\mathrm{MD}^{1}$, Elena Zeni $\mathrm{BSc}^{1}$, Stefano Leprotti $\mathrm{MD}^{2}$, Alfredo Potena $\mathrm{MD}^{3}$, Licia Ballerin $\mathrm{MD}^{3}$, Alberto Papi MD ${ }^{1}$, Giuseppina Palladini BSc ${ }^{4}$, Maurizio Luisetti $\mathrm{MD}^{5}$, Laura Annovazzi BSc ${ }^{6}$, Paolo Iadarola $\mathrm{ChSc}^{6}$, Edoardo De Rosa $\mathrm{MD}^{1}$, Leonardo M. Fabbri $\mathrm{MD}^{7}$, and Cristina E. Mapp $\mathrm{MD}^{1}$

1. Department of Experimental and Clinical Medicine, University of Ferrara, Ferrara; 2. Department of Surgery Anesthesiology and Radiology, University of Ferrara, Ferrara; 3. Section of Respiratory Physiopathology, University-Hospital of Ferrara, Ferrara; 4. Department of Internal Medicine, IRCCS San Matteo Hospital, University of Pavia, Pavia; 5. Department of Respiratory Diseases, IRCCS San Matteo Hospital, University of Pavia, Pavia; 6. Department of Biochemistry, University of Pavia, Pavia; 7. Department of Medicine, Oncology and Radiology, Section of Respiratory Diseases, University of Modena \& Reggio Emilia, Modena, Italy.

Correspondence and requests for reprints:

Piera Boschetto, MD

Dipartimento di Medicina Clinica e Sperimentale, Sezione di Igiene e Medicina del Lavoro, Via Fossato di Mortara 64/b, 44100 Ferrara, Italy.

Phone: +39 0532 291565; fax: +39 0532 205066; E-mail: bsp@unife.it

Running head: emphysema and COPD severity.

Word counts $=3741$ 


\begin{abstract}
Background: The predominant emphysema phenotype is associated with more severe airflow limitation in patients with chronic obstructive pulmonary disease (COPD). We investigated whether COPD patients with or without quantitatively HRCT scan-documented emphysema have different COPD severity, as assessed by BODE (body mass index, airflow obstruction, dyspnea, exercise performance) Index and inspiratory capacity-to-total lung capacity ratio (IC/TLC), and by different biological markers of lung parenchymal destruction.

Methods: We examined 26 outpatients with COPD and 8 healthy nonsmokers. Each subject underwent HRCT scan, pulmonary function tests, cell counts and measurements of neutrophil elastase, matrix metalloproteinase (MMP)-9 and tissue inhibitor of metalloproteinase (TIMP)-1 in induced sputum, as well as measurement of desmosine, a marker of elastin degradation in urine, plasma and sputum.

Results: As compared with subjects without HRCT documented emphysema and controls, patients with HRCT scan-documented emphysema had higher BODE Index and lower IC/TLC. Forced expiratory volume in one second $\left(\mathrm{FEV}_{1}\right), \mathrm{FEV}_{1} /$ forced vital capacity ratio, and carbon monoxide transfer coefficient were lower, whereas the number of eosinophils, MMP-9 and the MMP-9/TIMP1 ratio in sputum were higher in patients with emphysema. In COPD patients, the number of sputum eosinophils was the biological variable that correlated positively with the HRCT score of emphysema $(\mathrm{p}=0.04)$.

Conclusions: These results suggest that COPD associated with HRCT scan documented emphysema is characterized by more severe lung function impairment, more intense airway inflammation, and, possibly, more serious systemic dysfunctioning, as compared with COPD not associated with HRCT scan-documented emphysema.
\end{abstract}

Word counts: 242

Key words: chronic obstructive pulmonary disease, emphysema, biological markers, outcomes. 


\section{INTRODUCTION}

Chronic obstructive pulmonary disease (COPD) is characterized by the progressive development of airflow limitation that is not fully reversible.[1] Chronic airflow limitation may be caused by increased resistance of the small conducting airways and increased compliance of the lung due to emphysema.[1] We have previously shown that COPD patients with HRCT-documented emphysema have more severe airflow limitation.[2] Now we hypothesize that COPD patients with emphysema, as quantitatively assessed by HRCT, may be associated with more severe disease and may be characterized by biological markers of lung parenchymal destruction, measurable by noninvasive methods.

The BODE (body mass index, airflow obstruction, dyspnea, exercise performance) Index and the inspiratory capacity-to-total lung capacity ratio (IC/TLC) have been recently demonstrated to grade properly the severity of COPD, as a systemic and respiratory disease, and to predict the outcome in these patients.[3][4] The higher the BODE Index and the lower the IC/TLC ratio, the higher is the risk of death from any cause and respiratory causes in subjects with COPD.

There have been no studies aimed at exploring the possible relationship between the extent of emphysema and the severity of COPD, including variables such as BODE Index and IC/TLC. In the one study where it was shown that patients with emphysema have the lowest survival rate in subjects with COPD,[5] the diagnosis of emphysema had been based on clinical characteristics only. Thus, we planned first to quantify the severity and extent of emphysema on high resolution computed tomography (HRCT) density mask and then to investigate if patients with HRCT documented emphysema have higher BODE Index and lower IC/TLC as compared with patients without.

Recently, the application of sputum induction and refined methods of sputum examination have provided the opportunity to examine cell and molecular markers involved in the pathogenesis of COPD.[6] Neutrophil elastase (NE) and matrix metalloproteinase (MMP)-9 have been shown to be implicated in human emphysema,[7] their principal effect being the destruction of the extracellular matrix (ECM), particularly elastin. Desmosine, an elastin-derived, cross-link amino acid, is a specific marker of elastin degradation. We, therefore, hypothesized that COPD patients with emphysema may have higher levels of sputum NE and MMP-9 and desmosine in urine, plasma and sputum than patients without emphysema. Then, we investigated which of the biological markers showed the strongest association with the HRCT emphysema score.

\section{METHODS}

\section{Subjects}

Fifty patients with moderate-to-severe COPD [1] who presented to the outpatient Clinic of Respiratory Diseases of the University-Hospital of Ferrara, Italy, were submitted to high resolution computed tomography (HRCT) of the chest. Emphysema was indicated by a lung area greater than $15 \%$ showing attenuation values lower than -950 Hounsfield units (HU).[8] Among the fourteen COPD patients meeting the criterium for the HRCT diagnosis of emphysema, three patients did not complete the study; one because of unsuspected lung malignancy and the other two because they refused to continue. Among the thirty-six COPD patients without HRCT diagnosis of emphysema, we enrolled in the study the first consecutive fifteen subjects. Five patients (two with and three without emphysema) who completed the present study are also part of a group, the results of which have been reported earlier.[2] To quantify emphysema in a control group, we also carried out HRCT of the chest to eight age-matched healthy nonsmokers. The study was approved by the Ethics Committee of the University-Hospital of Ferrara and all patients gave their written informed consent. Patients were in clinically stable conditions and free from acute exacerbations in the 2 months preceding the study.

Each subject underwent medical history, including history of chronic bronchitis,[1] pulmonary function tests, induced sputum, and collection of venous blood and morning urine samples. All patients were non-atopic, skin prick test negative, and had no history of asthma. Three of the eleven COPD patients with, and five of the fifteen without emphysema, were being treated with low doses 
of inhaled glucocorticoids. None of the patients reported to have taken nonsteroidal antiinflammatory drugs in the month preceding the study. Plasma used for desmosine determination was obtained after centrifuging the blood specimens at $2500 \mathrm{rpm}$ for $10 \mathrm{~min}$. Samples were stored at $-20^{\circ} \mathrm{C}$ until use. The BODE (body-mass index, airflow obstruction, dyspnea, exercise capacity, measured by the six-minute-walk test) Index [3] was determined in COPD patients.

\section{Computed tomography}

A third-generation, continuous-rotation CT scanner with volume acquisition extendable to $50 \mathrm{~s}$ (Tomoscan SR7000, Philips, Einthoven, The Netherlands) was used. The quantitative evaluation of emphysema was based on 10-15 slices of $1.5-\mathrm{mm}$ thick sections that were acquired with $175-\mathrm{mA}$ tube current and $2 \mathrm{~s}$ scanning time, and were obtained at 2-cm interval levels from the apex through the base of the lung while the subject was breath-holding at full inspiration. For each lung at each level, the total area, the emphysematous area less than $-950 \mathrm{HU}$, and the mean lung density were assessed with standard CT software (Hitachi Medical Corporation). At each level, the percentage of emphysematous lung was calculated.[8][9] The overall degree of each subject's emphysema was expressed as a percentage of the total lung area assessed.

\section{Pulmonary function studies}

In each subject, lung volumes, both before and after $400 \mu \mathrm{g}$ of inhaled salbutamol, (Biomedin, Padova, Italy), the carbon monoxide transfer coefficient (Kco) by the single-breath technique, oxygen $\left(\mathrm{PaO}_{2}\right)$ and carbon dioxide $\left(\mathrm{PaCO}_{2}\right)$ tension of arterial blood (Instrumentations Laboratories, Milan, Italy) were measured as previously described,[10] according to published guidelines.[11][12]

\section{Sputum cell counts and mediator measurements}

Sputum was induced and processed in all subjects, as previously reported.[10] [13] Increasing concentrations of hypertonic saline were nebulized with an ultrasonic nebulizer (Mistogen Equipment Co., Oakland, CA, USA). Sputum supernatant was stored at $-80^{\circ} \mathrm{C}$ for later assays and the total content of proteins was evaluated by the Lowry method.[14]

The MMP-9 activity was detected by zymography, as previously described;[15] the gels were analyzed by GS 710 Densitomer (Bio-Rad). This assay measures both pro (latent) form (92 kDa) of MMP-9 and active MMP-9 form (80-88 kDa), but is insensitive to proteinase inhibitor complexes. In our samples, only the pro MMP-9 was present, no active form was noted in any lane. The lower detection limit of the assay was $2.5 \mathrm{ng} / \mathrm{ml}$, with a within-batch coefficient of variation of $15 \%$. The content of pro MMP-9, free and complexed with TIMP-1, and of total TIMP-1, free and complexed with metalloproteinases, was assessed by ELISA assay (Amersham Pharmacia Biotech).[16] The sensitivity was $0.6 \mathrm{ng} / \mathrm{ml}$ and $1.25 \mathrm{ng} / \mathrm{ml}$ for MMP-9 and TIMP-1, respectively. The within-batch coefficients of variation for MMP-9 and TIMP-1 were $0.1 \%$ and $1 \%$ and the between batch variations were $0.5 \%$ and $1.36 \%$, respectively.

NE activity in sputum was determined by the micellar electrokinetic chromatography method, using the synthetic substrate SucAla 3 NA, as previously described.[17] The lower detection limit of the method was $0.5 \mathrm{mU} / \mathrm{mL}$, with a within and between-batch coefficient of variation of $1 \%$.

Desmosines (resulting from the sum of the desmosine + isodesmosine levels) were determined in urine and plasma by the capillary electrophoresis method, coupled with laser-induced fluorescence, as previously described.[18][19] The limit of detection of the method was $10^{-8} \mathrm{M}$ (equivalent to 0.1 fmol on column), with a within and between-batch coefficient of variation of $2.5 \%$ and $3.5 \%$, respectively.

To determine the concentration of desmosines in sputum, $200 \mu \mathrm{l}$ of supernatant were deproteinized by addition of $0.45 \mathrm{M}$ trichloroacetic acid $(50 \mu \mathrm{l})$. The pellet obtained upon centrifugation for 10 min at $14000 \mathrm{rpm}$ was discarded; desmosine-containing soluble peptides included in the supernatant were transferred to pyrex tubes, evaporated to dryness in vacuo and hydrolyzed by refluxing with $200 \mu \mathrm{l}$ of twice distilled constant boiling $6 \mathrm{M} \mathrm{HCl}$ at $106^{\circ} \mathrm{C}$ for $24 \mathrm{~h}$. The hydrolyzed material was dried under a nitrogen stream, the residue washed 4 times with deionized water and neutralized with $0.5 \mathrm{M} \mathrm{Na}_{2} \mathrm{CO}_{3} \mathrm{pH} 8.7$, to give a final volume of $200 \mu \mathrm{l}$. After centrifuging for $15 \mathrm{~min}$ at $13000 \mathrm{rpm}$, 
the supernatant was derivatized with fluoresceine isothiocyanate (FITC) and analyzed on capillary electrophoresis following the same procedure described for urine and plasma.[18][19] Each sample was analyzed in triplicate. The yield of derivatization and the recovery of material were practically identical to those previously indicated for plasma.[18] Although the number of sputum samples so far analyzed was limited, the within and between-batch coefficients of variation were similar to those indicated for the other specimens.

The presence of severe alpha-1 antitrypsin deficiency (AATD) was excluded by laboratory diagnosis of AATD, including nephelometry, isoelectric focusing and genotyping on dried blood specimens.[20]

\section{Statistical analysis}

Group data are expressed as mean (SEM), or as median and interquartile range, when appropriate. Analysis of variance followed by the unpaired Student's t test for normally distributed data, and the Kruskall-Wallis test followed by the Mann-Whitney U test for not normally distributed were used to determine differences between groups. Categorical values were analyzed using Fisher's exact test. The correlation between HRCT emphysema score and the clinical, functional and biological variables was tested by Pearson correlation analysis; continuous variables not normally distributed were $\log$ transformed to achieve normality.[21] Probability values of $p<0.05$ were accepted as significant. The calculations were made with Statview for Windows, version 5 (SAS Institute Inc.; Cary, NC) and with MedCalc for Windows (by F. Schoonjans, Mariakerke, Belgium).

\section{RESULTS}

Based on the HRCT emphysema score, subjects were grouped as COPD with [score $27.2(1.8) \%$, mean (SEM); range 19.6-35.5\%], and COPD without emphysema [score $4.7(0.8) \%$; range 1.313.2\%]. The HRCT score in age-matched healthy nonsmokers was $2.4(0.7) \%$, (range 1.3-5.8\%) and it was not different from that of the COPD subjects without emphysema. The MLD averaged -886.1 (8.3) HU, -854.9 (4.7) HU, and -850.6 (11.5) HU, respectively in patients with and without emphysema and in controls ( $\mathrm{p}=0.004$ in emphysema versus the two latter groups).

There was no significant difference in smoking history between COPD patients with emphysema and patients with no emphysema [pack-years, mean (SEM), 49 (10) and 33 (7), respectively]. All patients were ex-smokers, except two current smokers in the group of no emphysema.

COPD patients with emphysema had higher BODE Index and lower inspiratory capacity-to-total lung capacity (IC/TLC) (Figure). They had lower body-mass index (BMI), lower forced expiratory volume in one second $\left(\mathrm{FEV}_{1}, \%\right.$ predicted), more dyspnea, according to the modified Medical Research Council (MMRC) scale,[22] and walked similar distance in six minutes as compared with patients with no emphysema (Table 1).

Emphysema patients had lower $\mathrm{FEV}_{1}$ /forced vital capacity (FVC) ratio (\%), and $\mathrm{Kco}$ (\% predicted) than patients with no emphysema. For similar values of total lung capacity (TLC) in the two groups, functional residual capacity (FRC, \% predicted) and residual volume (VR, \% predicted) were significantly higher in COPD patients with emphysema (Table 1). Conversely, the two groups of patients had similar levels of arterial blood gases (Table 1) and similar response to inhaled bronchodilator, i.e. a change in $\mathrm{FEV}_{1}$ less than $200 \mathrm{ml}$ and $12 \%$ baseline/predicted. Two of the 11 COPD patients with and six of the 15 without emphysema had symptoms of chronic bronchitis.

All the studied subjects were able to produce sputum, except one emphysematous patient. Patients with emphysema had more sputum eosinophils and less sputum macrophages (Table 2). They had greater MMP-9 concentration and MMP-9/TIMP-1 ratio than COPD patients without emphysema (Table 3) and healthy non-smokers [median (interquartile range): 91.41 (39.55-153.62) ng/ml, $\mathrm{p}=$ 0.01 and $4.25(1.82-22.89), \mathrm{p}=0.01]$. Both groups of COPD patients had higher MMP-9 activity [median (interquartile range): 6.05 (4.23-7.9) and 5.68 (3.67-7.39) optical density (OD) $x$ $\mathrm{mm}^{2} /$ protein $\mathrm{mg} / \mathrm{ml}$, for emphysema and no emphysema, respectively], as compared to control subjects [3 (1.57-3.48) OD $\times \mathrm{mm}^{2} /$ protein $\mathrm{mg} / \mathrm{ml} ; \mathrm{p}=0.003$ and $\mathrm{p}=0.01$, respectively]. 
Free neutrophil elastase activity was detected in five of the ten sputum samples of COPD patients with emphysema, in two of the fifteen samples of patients without emphysema, and in one of the eight healthy non-smokers (data not shown).

Given our familiarity with capillary electrophoresis, it was the method of choice for the detection of desmosines concentration in sputum, although this technique was never used before to measure the cited crosslinks in this matrix. Interestingly, the values obtained, although somewhat lower, were in good agreement with those reported by other authors, who used mass spectrometry to determine the amount of desmosines in sputum of five COPD patients.[23] Thus, based on our results, the levels of these specific crosslinks in sputum, urine and plasma were found to be similar in patients with and without emphysema (Table 3), although they were significantly increased in both groups of patients as compared to healthy non-smokers. The median (interquartile range) levels of desmosines in the latter group were: $5.26(3.9-5.99) \mathrm{ng} / \mathrm{mg}$ protein for sputum; $25.41(21.04-33.75) \mu \mathrm{g} / \mathrm{g}$ creatinine for urine; and 18.34 (11.86-21.16) $\mathrm{ng} / \mathrm{ml}$ for plasma.

None of the patients was affected by AATD; nevertheless, we found four patients (two with and two without emphysema) carrying intermediate AATD, i.e. two PI*MS, one PI*MZ, and one PI*MR (where $\mathrm{R}$ denotes a rare, non-S and non- $Z$ deficiency allele). However, the mean serum levels of alpha-1 antitrypsin did not differ between patients with and without emphysema [mean (SEM), 169.5 (15.4) and 163.3 (16.7) $\mathrm{mg} / \mathrm{dl}$, respectively; normal values 83-199 mg/dl].

The correlation analysis involving the 26 COPD patients shows strong associations between the HRCT emphysema score and both BODE Index and IC/TLC ratio (Table 4). Table 4 also reports the significant correlations of HRCT score with functional parameters. Among the biological markers, sputum eosinophils showed a positive association with the HRCT score (Table 4). The number of sputum eosinophils also correlated with IC/TLC $(r=-0.401, p=0.04)$. However, when the group of patients with emphysema and the group of patients without emphysema were considered separately, no correlation between HRCT emphysema score and BODE index, IC/TLC and sputum parameters was observed.

Table 1. Characteristics of patients with chronic obstructive pulmonary disease divided according to the presence or absence of emphysema on high resolution computed tomography examination

\begin{tabular}{|c|c|c|c|}
\hline & $\begin{array}{l}\text { Emphysema } \\
\quad(\mathrm{n}=11)\end{array}$ & $\begin{array}{l}\text { No emphysema } \\
(\mathrm{n}=15)\end{array}$ & $\mathrm{p}$ Value \\
\hline Age, yr & $71(3)$ & $70(2)$ & NS \\
\hline Sex, M/F & $10 / 1$ & $12 / 3$ & \\
\hline BMI, $\mathrm{kg} / \mathrm{m}^{2}$ & $24.49(1.20)$ & $28.13(0.63)$ & 0.008 \\
\hline Dyspnea, MMRC & $3(0.4)$ & $2(0.2)$ & 0.03 \\
\hline $6 \mathrm{MWD}, \mathrm{m}$ & $357(42)$ & $395(23)$ & NS \\
\hline $\mathrm{FEV}_{1}, \%$ predicted & $31.27(2.62)$ & $47.07(3.82)$ & 0.004 \\
\hline $\mathrm{FEV}_{1} / \mathrm{FVC}, \%$ & $37.15(1.9)$ & $49.47(2)$ & 0.0002 \\
\hline FRC, \% predicted & $139.64(7.04)$ & $112.47(4.3)$ & 0.002 \\
\hline $\mathrm{K}_{\mathrm{CO}}, \%$ predicted & $31.73(5.16)$ & $54.4(4.33)$ & 0.002 \\
\hline $\mathrm{RV}, \%$ predicted & $152.91(7.9)$ & $131.13(5.78)$ & 0.03 \\
\hline $\mathrm{PaO}_{2}, \mathrm{mmHg}$ & $72.5(3)$ & $76.43(3.25)$ & NS \\
\hline $\mathrm{PaCO}_{2}, \mathrm{mmHg}$ & $41.8(1.83)$ & $38.65(1.1)$ & NS \\
\hline \multicolumn{4}{|c|}{$\begin{array}{l}\text { Definition of abbreviations: } \mathrm{NS}=\text { not significantly different; } \mathrm{M}=\text { male; } \mathrm{F}=\text { female; } \mathrm{BMI}=\text { body } \\
\text { mass index; } \mathrm{MMRC}=\text { Modified Medical Research Council; } 6 \mathrm{MWD}=6 \text {-minute walk distance; } \\
\mathrm{FEV}_{1}=\text { forced expiratory volume in one second; } \mathrm{FVC}=\text { forced vital capacity; } \mathrm{FRC}=\text { functional } \\
\text { residual capacity; } \mathrm{K}_{\mathrm{CO}}=\text { carbon monoxide diffusion constant; } \mathrm{RV}=\text { residual volume; } \mathrm{PaO}_{2}= \\
\text { arterial oxygen tension: } \mathrm{PaCO}_{2}=\text { arterial carbon dioxide tension. }\end{array}$} \\
\hline
\end{tabular}
Data are presented as mean (SEM); comparisons with Unpaired t-test. 
Table 2. Sputum cell counts in chronic obstructive pulmonary disease patients divided according to the presence or absence of emphysema on high resolution computed tomography examination

\begin{tabular}{lccc}
\hline & $\begin{array}{c}\text { Emphysema } \\
(\mathrm{n}=10)\end{array}$ & $\begin{array}{c}\text { No emphysema } \\
(\mathrm{n}=15)\end{array}$ & $\mathrm{p}$ Value \\
\hline Total nonsquamous cells, $\times 10^{3} / \mathrm{mg}$ & $24.4(15.7-29.5)$ & $17.7(12.9-25.5)$ & $\mathrm{NS}$ \\
Macrophages, $\times 10^{3}$ cells/mg & $1.6(0.9-2.4)$ & $2.7(1.8-4.6)$ & 0.04 \\
Neutrophils, $\times 10^{3}$ cells/mg & $21.2(13.2-23.8)$ & $13.3(9-21.1)$ & $\mathrm{NS}$ \\
Eosinophils, $\times 10^{3}$ cells/mg & $0.8(0.3-1.9)$ & $0.2(0-0.6)$ & 0.02 \\
Lymphocytes, $\times 10^{3}$ cells/mg & $0.1(0-0.1)$ & $0(0-0.1)$ & NS \\
\hline
\end{tabular}

Definition of abbreviations: NS = not significantly different.

Data are presented as median (interquartile range); comparisons with Mann-Whitney U-test.

Table 3. Mediator findings in chronic obstructive pulmonary disease patients divided according to the presence or absence of emphysema on high resolution computed tomography examination

\begin{tabular}{lccc}
\hline Variable $^{*}$ & $\begin{array}{c}\text { Emphysema } \\
(\mathrm{n}=10)\end{array}$ & $\begin{array}{c}\text { No emphysema } \\
(\mathrm{n}=15)\end{array}$ & $\mathrm{p}$ Value \\
\hline MMP-9, ng/ml & $220.92(175.51-293.26)$ & $72.21(41.85-165.44)$ & 0.04 \\
TIMP-1, ng/ml & $2.33(1.43-19.73)$ & $7.47(4.45-12.73)$ & $\mathrm{NS}$ \\
MMP-9/TIMP-1 ratio & $58.74(20.1-171.47)$ & $7.62(4.31-28.2)$ & 0.01 \\
MMP-9 activity, OD x mm ${ }^{2} / \mathrm{protein} \mathrm{mg} / \mathrm{ml}$ & $6.05(4.23-7.9)$ & $5.68(3.67-7.39)$ & $\mathrm{NS}$ \\
NE activity, U/ml & $0.01(0-0.29)$ & $0(0-0)$ & $\mathrm{NS}$ \\
Desmosines, $\mathrm{ng} / \mathrm{mg}$ protein & $12.21(7.98-13.12)$ & $6.31(5.79-13.03)$ & $\mathrm{NS}$ \\
Urinary desmosines, $\mu \mathrm{g} / \mathrm{g}$ creatinine & $55.82(37.74-74.33)$ & $38.66(34.3-54.86)$ & $\mathrm{NS}$ \\
Plasma desmosines, $\mathrm{ng} / \mathrm{ml}$ & $40.03(22.78-57.04)$ & $29.45(20.51-40.93)$ & $\mathrm{NS}$ \\
\hline
\end{tabular}

Definition of abbreviations: MMP-9 = matrix metalloproteinase-9; TIMP-1 = tissue inhibitor metalloproteinase-1; NS = not significantly different; OD = optical density; NE = neutrophil elastase.

${ }^{*}$ Variables measured in sputum except when indicated.

Data are presented as median (interquartile range); comparisons with Mann-Whitney U-test.

Table 4. Significant relationships between high resolution computed tomography emphysema score $^{*}$ and clinical and biological variables in chronic obstructive pulmonary disease patients

Clinical variables

$\begin{array}{lcc}\text { BODE Index } & 0.589 & 0.008 \\ \text { BMI, kg/m² } & -0.525 & 0.006 \\ \text { Dyspnea, MMRC } & 0.581 & 0.004 \\ \text { IC/TLC } & -0.557 & 0.003 \\ \mathrm{FEV}_{1}, \% \text { predicted } & -0.480 & 0.013 \\ \mathrm{FEV}_{1} / \mathrm{FVC}, \% & -0.659 & 0.0003 \\ \mathrm{FRC}^{2} \% \text { predicted } & 0.587 & 0.002 \\ \mathrm{~K}_{\mathrm{CO}}, \% \text { predicted } & -0.615 & 0.0008 \\ \mathrm{RV}, \% \text { predicted } & 0.414 & 0.03\end{array}$

Biological variables

Eosinophils, $\mathrm{x} 10^{3}$ cells $/ \mathrm{mg}^{\dagger}$

0.409

0.04

Definition of abbreviations: BODE = body mass index, airflow obstruction, dyspnea, exercise performance; $\mathrm{BMI}=$ body mass index; $\mathrm{MMRC}=$ Modified Medical Research Council; IC/TLC $=$ 
inspiratory capacity/total lung capacity; $\mathrm{FEV}_{1}=$ forced expiratory volume in one second; $\mathrm{FVC}=$ forced vital capacity; $\mathrm{FRC}=$ functional residual capacity; $\mathrm{K}_{\mathrm{CO}}=$ carbon monoxide diffusion constant; RV = residual volume.

*Range: $1.3-35.5 \%$; ${ }^{\dagger} \log$ transformed value.

\section{DISCUSSION}

In this study, the authors have shown that COPD patients with HRCT-documented emphysema have higher BODE Index and lower IC/TLC ratio as compared with subjects without HRCTdocumented emphysema. COPD patients with emphysema had lower $\mathrm{FEV}_{1}, \mathrm{FEV}_{1} / \mathrm{FVC}$, and Kco, higher FRC, an increased number of eosinophils and an increased MMP-9 concentration and MMP9/TIMP-1 ratio in induced sputum.

We have previously shown that COPD patients with emphysema, defined by an HRCT visual score, have a higher degree of airflow limitation. In the present study, using CT scanning with density mask, that provides an objective, non-invasive, quantitative method to diagnose and quantify emphysema in vivo,[24] we confirm this result.

Our findings of a combination of functional measurements reflecting a decrease in maximum flow, a degree of lung hyperinflation and a decrease in lung diffusing capacity in patients with HRCTdocumented emphysema are in agreement with the results of a recent study that focused on the relationship between severity and extent of emphysema, as assessed by HRCT scanning and lung function data.[25] In addition we found that, in COPD patients, abnormal pulmonary function parameters characteristic of emphysema, i.e. $\mathrm{FEV}_{1}, \mathrm{FEV}_{1} / \mathrm{FVC}$, Kco and FRC, correlate with BODE Index and IC/TLC (data not shown) supporting the hypothesis that the emphysema phenotype is associated with a more severe disease.

The body-mass index was significantly lower and the score on the MMRC dyspnea scale significantly higher in patients with as compared to patients without emphysema. Furthermore, these BODE variables correlate with the HRCT emphysema score, suggesting a more important systemic involvement in emphysematous patients. In these subjects, 6-minute walk distance was lower, but not significantly so, indicating that exercise capacity, as assessed by 6MWT, was slightly impaired in emphysema as compared with no emphysema subjects. However, we are aware that formal cardiopulmonary exercise testing should be performed to provide a global evaluation of the exercise capacity.[26] Thus, further investigations are needed to evaluate a difference in exercise capacity between the two COPD phenotypes.

The most accepted hypothesis for the pathogenesis of emphysema is the proteinase/proteinase inhibitor hypothesis.[27] In this hypothesis, emphysema develops as a result of excessive proteinase burden which leads to a proteinase/proteinase inhibitor imbalance.

This study, using induced sputum, demonstrated a significant increase in MMP-9 concentration and MMP-9/TIMP-1 ratio in COPD patients with emphysema. An increase in BAL concentrations and macrophage expression of MMP-9 (gelatinase B) has been reported in patients with emphysema as compared to normal volunteers.[28][29] Our results, obtained by a noninvasive method, such as sputum induction, extend this finding. Indeed, MMP-9 levels and MMP-9/TIMP-1 ratio were higher in COPD patients with emphysema than in both controls and COPD patients without emphysema, thus suggesting an amplified protease imbalance in the emphysema phenotype of COPD. There was no difference in MMP-9 activity between the two groups of patients, i.e. emphysema and no emphysema. It is likely that the MMP-9 activation occurring in the alveolar compartment macrophages of emphysematous patients could not be measurable in induced sputum, as the enzyme is rapidly inactivated. The present COPD patients showed a positive correlation between MMP-9 activity and the percentage of neutrophils $(r=0.729, p<0.0001)$, suggesting that MMP-9 activity in sputum may originate mainly from activated neutrophils, which are typically located in the airway lumen of subjects with COPD,[30] and so are detectable in the sputum. Another possible explanation for the low levels of MMP-9 activity, similar in the two groups of patients, is that most of the enzyme present in sputum samples is still in the latent, pro-form. 
Neutrophil elastase activity and desmosines were similar in emphysema and no emphysema subjects. Although neutrophil elastase has been prominent in the understanding of the pathogenesis of emphysema since 40 years ago,[31][32] its association with human emphysema has been inconsistent.[7] It could be argued that the measurement of elastolytic activity in induced sputum may not accurately assess the activity in the interstitium, the site of extracellular matrix degradation in emphysema. However, the study which showed neutrophil elastase in close association with elastic fibers in the interstitium, in an amount that correlates with the severity of emphysema,[33] has been questioned in another study, that failed to reproduce these findings. [34] Furthermore, homogenates of lung removed in volume reduction surgery revealed significant elevations in MMP9, with no significant increase in neutrophil elastase.[35] In our patients, only negligible levels of unopposed neutrophil elastase activity could be detected. It is therefore likely that in these stable patients, neutrophil elastase was efficiently and almost totally inhibited by naturally occurring inhibitors, such as alpha-1 antitrypsin and SLPI. In fact, excess free elastase activity can be detected at high levels in lung secretions particularly during acute bacterial exacerbations.[36]

Desmosine, an elastin-derived, cross-linked amino acid, has been shown to be elevated in the urine of patients with COPD.[37][38] Our study confirms and extends these results, demonstrating an increase of desmosines also in induced sputum, a more immediate site of the disease, following the preliminary results obtained in spontaneous sputum by HPLC-mass spectrometry.[23] No difference, however, was observed in desmosines, measured in sputum, urine and plasma, between patients with and without emphysema. These findings are in agreement with those reported by Gottlieb et al.[39] Indeed, they showed that, among smokers with a rapid decline in lung function, there was no difference in desmosine excretion between those with and those without computed tomographic evidence of emphysema, suggesting that elastin degradation may occur both in emphysema and in airway disease. In contrast, Cocci and coworkers described a negative correlation between urinary excretion of desmosine and extent of emphysema.[40] They used an ELISA method to quantify urine desmosine and studied patients admitted for acute exacerbation or under evaluation for lung transplant. Therefore, differences in methodology and patients' selection might explain these discrepancies. In our hands, sputum, urine and plasma desmosines correlated positively with the HRCT emphysema score when all the studied subjects were considered together. Interestingly, desmosines also correlated negatively with $\mathrm{FEV}_{1} / \mathrm{FVC}$ and positively with $\mathrm{FRC} \%$ and $\mathrm{RV} \%$ (data not shown). These data suggest a meaningful value of desmosine as a biological marker of lung destruction in emphysema, although its role in supporting the diagnosis, monitoring the disease progress and assessing the efficacy of therapeutic interventions needs to be further investigated.

With regard to cellular sputum analysis, this study demonstrated a significant increase in the number of sputum eosinophils in patients with emphysema. The finding of eosinophilic inflammation in the airways of COPD patients strongly supports the so-called "Dutch hypothesis", i.e. smokers with an allergic diathesis have a greater predisposition to develop severe and chronic airflow obstruction.[41][42] However, our patients were not-atopic and the role of eosinophils in COPD is not well-established. There are some reports of increased number of eosinophils in the airways, lavage and induced sputum of patients with stable COPD, whereas others have not found increased number in airway biopsies and bronchoalveolar lavage.[43][44] We found that the number of sputum eosinophils was elevated in emphysema, as compared with both no emphysema and control subjects, whereas it was not different between COPD patients with no emphysema and healthy non-smokers. Furthermore, the number of sputum eosinophils correlated positively with the HRCT emphysema score. Interestingly, in situ hybridization for lung MMP-9 mRNA in a small group of patients with emphysema did show a correlation with emphysema histologic grade and an eosinophilic source of the protein.[45] On the other hand, MMP-9 is implicated in the chemotaxis of eosinophils,[46] and MMP-9 levels were increased in our patients with emphysema. Finally, the number of sputum eosinophils significantly correlated with the IC/TLC ratio, thus supporting a possible role of eosinophils in the outcome of COPD. 
We recognize some limitations of our study. Firstly, we performed a cross-sectional study which does not allow us to exclude the weight of COPD progression in our findings. To try to rule out the bias of the different $\mathrm{FEV}_{1}$ between patients with and without emphysema, we compared the emphysema group with a subgroup $(\mathrm{n}=11)$ of the patients without emphysema matched for $\mathrm{FEV}_{1}$. The significant differences in the clinical and functional parameters and in the number of sputum eosinophils were confirmed (data not shown), despite the less number of patients. Secondly, because of the small number of observations, we cannot establish whether the lack of correlation between the HRCT score of emphysema and BODE Index, IC/TLC and sputum parameters, when the group of patients with and those without emphysema were considered separately, was due to the small sample size or to a nonexistent relationship. Nevertheless, the patients with COPD and HRCT-documented emphysema had 1) higher BODE Index, 2) lower IC/TLC, FEV $1, \mathrm{FEV}_{1} / \mathrm{FVC}$, $\mathrm{DL}_{\mathrm{CO}}$ and 3) higher number of eosinophils, MMP-9 and MMP-9/TIMP-1 ratio in induced sputum than subjects without HRCT- documented emphysema.

In conclusion, COPD patients with emphysema have more severe lung function impairment, more intense airway inflammation, and, possibly, more serious systemic dysfunctioning. 


\section{Sponsors}

Supported by the Italian Ministry of University and Research, A.R.C.A., and Consorzio Ferrararicerche.

\section{Acknowledgements}

The authors would like to thank E. Forini for her help in the statistical analysis and O. Di Maria and I. Ferrarotti for their technical assistance.

\section{Ethics approval}

The study was approved by the Ethics Committee of the University-Hospital of Ferrara and all patients gave their written informed consent.

\section{Competing interests}

None declared.

Figure legend

(A) BODE (body mass index, airflow obstruction, dyspnea, exercise performance) Index and (B) IC/TLC (inspiratory capacity/total lung capacity) ratio in chronic obstructive pulmonary disease patients divided according to the presence or absence of emphysema on high resolution computed tomography examination. Data are presented as mean $(\mathrm{SEM}) ;{ }^{*} \mathrm{p}=0.02 ;{ }^{* *} \mathrm{p}=0.004$. 


\section{REFERENCES}

1 Pauwels RA, Buist AS, Calverley PM, et al. Global strategy for the diagnosis, management, and prevention chronic obstructive pulmonary disease. NHLBI/WHO Global Initiative for Chronic Obstructive Lung Disease (GOLD) Workshop Summary. Am J Respir Crit Care Med 2001;163:1256-76.

2 Boschetto P, Miniati M, Miotto D, et al. Predominant emphysema phenotype in chronic obstructive pulmonary disease patients. Eur Respir J 2003;21:450-4.

3 Celli BR, Cote CG, Marin JM, et al. The body-mass index, airflow obstruction, dyspnea, and exercise capacity index in chronic obstructive pulmonary disease. $N$ Engl J Med 2004;350:1005-12.

4 Casanova C, Cote C, de Torres JP, et al. Inspiratory-to-total lung capacity ratio predicts mortality in patients with chronic obstructive pulmonary disease. Am J Respir Crit Care Med 2005;171:591-7.

5 Burrows B, Bloom JW, Traver GA, et al. The course and prognosis of different forms of chronic airways obstruction in a sample from the general population. $N$ Engl $\mathrm{J}$ Med 1987;317:1309-14.

6 Barnes PJ, Shapiro SD, Pauwels RA. Chronic obstructive pulmonary disease: molecular and cellular mechanisms. Eur Respir J 2003;22:672-88.

7 Shapiro SD. Proteinases in chronic obstructive pulmonary disease. Biochem Soc Trans 2002;30:98-102.

8 Gevenois PA, Scillia P, de Maertelaer V, et al. The effects of age, sex, lung size, and hyperinflation on CT lung densitometry. AJR 1996;167:1169-73.

9 Madani A, Keyzer C, Gevenois PA. Quantitative computed tomography assessment of lung structure and function in pulmonary emphysema. Eur Respir J 2001;18:720-30.

10 Siafakas NM, Vermeire P, Pride NB, et al. Optimal assessment and management of chronic obstructive pulmonary disease (COPD). The European Respiratory Society Task Force. Eur Respir J 1995;8:1398-420.

11 Quanjer PH, Tammeling GJ, Cotes JE, et al. Lung volumes and forced ventilatory flows. Report Working Party Standardization of Lung Function Tests, European Community for Steel and Coal. Official Statement of the European Respiratory Society. Eur Respir J Suppl 1993;16:5-40.

12 Cotes JE, Chinn DJ, Quanjer PH, et al. Standardization of the measurement of transfer factor (diffusing capacity). Report Working Party Standardization of Lung Function Tests, European Community for Steel and Coal. Official Statement of the European Respiratory Society. Eur Respir J Suppl 1993;16:41-52.

13 Rytila PH, Lindqvist AE, Laitinen LA. Safety of sputum induction in chronic obstructive pulmonary disease. Eur Respir J 2000;15:1116-9.

14 Lowry OH, Rosebrough NJ, Farr AL, et al. Protein measurement with the Folin Phenol reagent. J Biol Chem 1951;193:265-75.

15 Kleiner DE, Stetler-Stevenson WG. Quantitative zymography: detection of picogram quantities of gelatinases. Anal Biochem 1994;218:325-9.

16 Vignola AM, Riccobono L, Mirabella A, et al. Sputum metalloproteinase-9/tissue inhibitor of metalloproteinase-1 ratio correlates with airflow obstruction in asthma and chronic bronchitis. Am J Respir Crit Care Med 1998;158:1945-50.

17 Viglio S, Luisetti M, Zanaboni G, et al. Simultaneous determination of Pseudomonas aeruginosa elastase, human leukocyte elastase and cathepsin $\mathrm{G}$ activities by micellar electrokinetic chromatography. J Chromatogr A 1999;846:125-34.

18 Annovazzi L, Viglio S, Perani E, et al. Capillary electrophoresis with laser-induced fluorescence detection as a novel sensitive approach for the analysis of desmosines in real samples. Electrophoresis 2004;25:683-91. 
19 Annovazzi L, Viglio S, Gheduzzi D, et al. High levels of desmosines in urine and plasma of patients with pseudoxanthoma elasticum. Eur J Clin Invest 2004;34:156-64.

20 American Thoracic Society/European Respiratory Society Statement. Standards for the diagnosis and management of individuals with alpha-1 antitrypsin deficiency. Am J Respir Crit Care Med 2003;168:818-900.

21 Armitage P, Berry G. Statistical methods in medical research. 3rd ed. Blackwell 1994.

22 Mahler DA, Wells CK. Evaluation of clinical methods for rating dyspnea. Chest 1988;93:580-6.

23 Ma S, Lieberman S, Turino GM, et al. The detection and quantitation of free desmosine and isodesmosine in human urine and their peptide-bound forms in sputum. Proc Natl Acad Sci USA 2003;100:12941-3.

24 Muller NL, Staples CA, Miller RR, et al. "Density mask". An objective method to quantitate emphysema using computed tomography. Chest 1988;94:782-7.

25 Cerveri I, Dore R, Corsico A, et al. Assessment of emphysema in COPD: a functional and radiologic study. Chest 2004;125:1714-8.

26 American Thoracic Society. ATS statement: guidelines for the six-minute walk test. Am J Respir Crit Care Med 2002;166:111-7.

27 Hogg JC, Senior RM. Chronic obstructive pulmonary disease - part 2: pathology and biochemistry of emphysema. Thorax 2002;57:830-4.

28 Finlay GA, Russell KJ, McMahon KJ, et al. Elevated levels of matrix metalloproteinases in bronchoalveolar lavage fluid of emphysematous patients. Thorax 1997;52:502-6.

29 Finlay GA, O’Driscoll LR, Russell KJ, et al. Matrix metalloproteinase expression and production by alveolar macrophages in emphysema. Am J Respir Crit Care Med 1997;156:240-7.

30 Saetta M, Turato G, Maestrelli P, et al. Cellular and structural bases of chronic obstructive pulmonary disease. Am J Respir Crit Care Med 2001;163:1304-9.

31 Gross P, Pfitzer EA, Tolker E, et al. Experimental emphysema: its production with papain in normal and silicotic rats. Arch Environ Health 1965;11:50-8.

32 Laurell CB, Eriksson S. The electrophoretic alpha 1-globulin pattern of serum in alpha 1antitrypsin deficiency. Scand J Clin Lab Invest 1963;15:132-40.

33 Damiano VV, Tsang A, Kucich U, et al. Immunolocalization of elastase in human emphysematous lungs. J Clin Invest 1986;78:482-93.

34 Fox B, Bull TB, Guz A, et al. Is neutrophil elastase associated with elastic tissue in emphysema? J Clin Pathol 1988;41:435-40.

35 Ohnishi K, Takagi M, Kurokawa Y, et al. Matrix metalloproteinase-mediated extracellular matrix protein degradation in human pulmonary emphysema. Lab Invest 1998;78:1077-87.

36 Hill AT, Campbell EJ, Bayley DL, et al. Evidence for excessive bronchial inflammation during an acute exacerbation of chronic obstructive pulmonary disease in patients with $\alpha_{1^{-}}$ antitrypsin deficiency (PiZ). Am J Respir Crit Care Med 1999;160:1968-75.

37 Stone PJ, Gottlieb DJ, O'Connor GT, et al. Elastin and collagen degradation products in urine of smokers with and without chronic obstructive pulmonary disease. Am J Respir Crit Care Med 1995;151:952-9.

38 Viglio S, Iadarola P, Lupi A, et al. MEKC of desmosine and isodesmosine in urine of chronic destructive lung disease patients. Eur Respir J 2000;15:1039-45.

39 Gottlieb DJ, Stone PJ, Sparrow D, et al. Urinary desmosine excretion in smokers with and without rapid decline in lung function: the Normative Aging Study. Am J Respir Crit Care Med 1996;154:1290-5.

40 Cocci F, Miniati M, Monti S, et al. Urinary desmosine excretion is inversely correlated with the extent of emphysema in patients with chronic obstructive pulmonary disease. Int $J$ Biochem Cell Biol 2002;34:594-604.

41 Postma DS, Boezen HM. Rationale for the Dutch Hypothesis. Chest 2004;126:96-104S. 
42 Jindal SK. Dutch Hypothesis. Chest 2004;126:329-30.

43 Turato G, Zuin R, Saetta M. Pathogenesis and pathology of COPD. Respiration 2001;68:117-28.

44 Fujimoto K, Yasuo M, Urushibata K, et al. Airway inflammation during stable and acutely exacerbated chronic obstructive pulmonary disease. Eur Respir J 2005;25:640-6.

45 Rosenbluth DB, Shapiro SD, Hogg JC, et al. Expression of the mRNA for the $92 \mathrm{kD}$ gelatinase is increased in emphysema [abstract]. Am $J$ Respir Crit Care Med 1995;151:A529.

46 Okada S, Kita H, George TJ, et al. Migration of eosinophils through basement membrane components in vitro: role of matrix metalloproteinase-9. Am J Respir Cell Mol Biol 1997;17:519-28.

\section{Copyright}

The Corresponding Author has the right to grant on behalf of all authors and does grant on behalf of all authors, an exclusive licence on a worldwide basis to the BMJ Publishing Group Ltd and its Licensees to permit this article to be published in Thorax editions and any other BMJPGL products to exploit all subsidiary rights, as set out in our licence http://thorax.bmjjournals.com/ifora/licence.pdf 
A

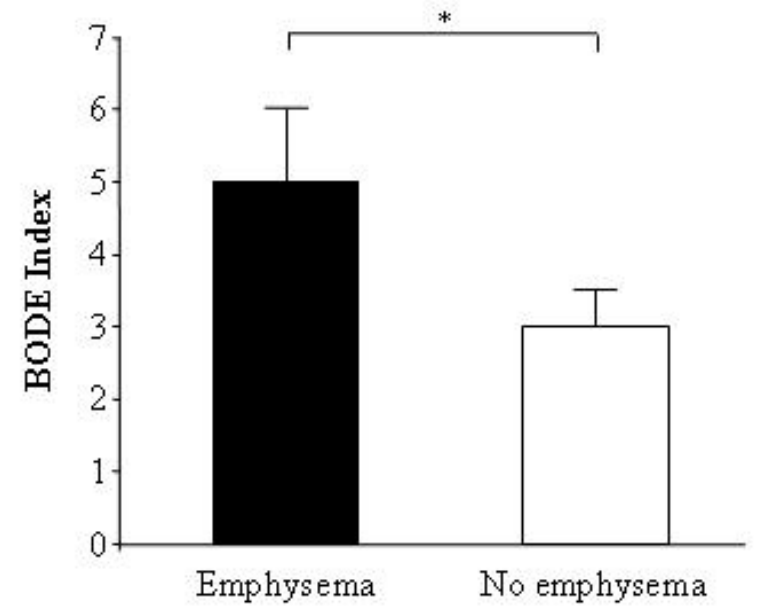

B

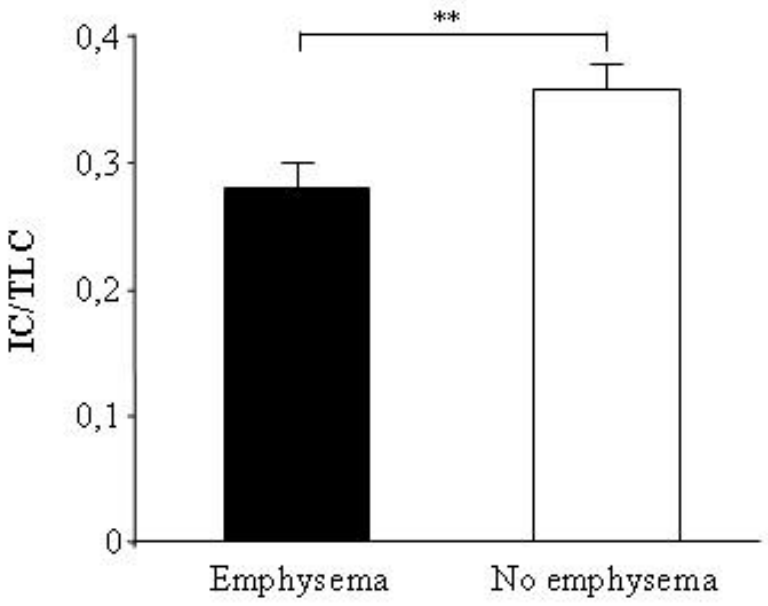

